\title{
Trends in the use and cost of antipsychotics among older adults from 2007 to 2013: a repeated cross-sectional study
}

\author{
Paul D. Foster BSc, Ximena Camacho MMath, Simone Vigod MD MSc, Zhan Yao MD MSc, \\ David N. Juurlink MD PhD, J. Michael Paterson MSc, Muhammad M. Mamdani PharmD MPH, \\ Diana Martins MSc, Tara Gomes MHSc
}

\section{Abstract}

Background: Recently, several new atypical antipsychotic agents have been introduced in Ontario, and regulatory warnings have been issued regarding use of atypical antipsychotics in older adults. We sought to establish the impact of newer atypical antipsychotics on prescribing rates and costs.

Methods: We performed a population-based cross-sectional study of Ontario adults aged 65 years or more using atypical antipsychotics from Jan. 1, 2007, to Mar. 31, 2013. These people have universal access to publicly funded drugs through the Ontario Health Insurance Plan and the Ontario Drug Benefit. We conducted time-series analysis to assess the impact of the introduction of new atypical antipsychotics on rates of use of atypical antipsychotics and associated expenditures.

Results: Rates of atypical antipsychotic use increased following the introduction of new agents in 2009 , from 27.6 users per 1000 older adults in the third quarter of 2009 to 29.1 users per 1000 older adults at the end of the study period $(p=0.04)$. Although prescribing rates for the newer atypical agents (paliperidone, ziprasidone and aripiprazole) remained low relative to their older counterparts (risperidone, olanzapine and quetiapine), rates of aripiprazole use rose to 1.0 user per 1000 older adults by the end of the study period. The proportion of prescriptions that were for brand-name agents fell from $57.5 \%$ in the second quarter of 2007 to $6.1 \%$ in the second quarter of 2009 , and then rose to $11.7 \%$ by the end of the study period. By the first quarter of 2013 , newer atypical antipsychotic agents were used by $4.4 \%$ of atypical antipsychotic users but accounted for $14.1 \%$ ( $\$ 1.2$ million of $\$ 8.5$ million) of atypical antipsychotic expenditures.

Interpretation: Although the overall prevalence of use of new atypical antipsychotic agents remains low, their introduction has led to increased prescribing of this class of drugs in older adults. Given the potential cost implications, further study of these trends would be prudent.

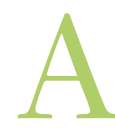

ntipsychotic drug therapy is a mainstay in the treatment of psychosis and related disorders. Since the introduction of atypical antipsychotics, in the 1990s, the use of and costs associated with these drugs have increased substantially. ${ }^{1-6}$ This increase has been driven primarily by prescriber preference for atypical (or second-generation) antipsychotics, ${ }^{1,2}$ higher costs of newer agents compared with typical (or first-generation) antipsychotics ${ }^{1}$ and a widening range of on- and off-label uses. ${ }^{3-5,7-9}$ The increase in the use of atypical antipsychotic medications has been particularly marked in older adults with dementia. ${ }^{8,10-12}$

Since the early 2000s, there has been a growing appreciation for antipsychotic-related adverse effects among older people with dementia, which prompted warnings from the manufacturers and Health Canada regarding the safety of risperidone and olanzapine in 2002 and 2004, respectively. In 2005, Health Canada urged caution in using risperidone, olanzapine or quetiapine in elderly patients with dementia. ${ }^{2}$ Although concerns around safety slowed the growth of anti- psychotic prescribing, rates of use increased between 2000 and 2007.2

Between 2007 and 2013, several changes to antipsychotic availability and funding affected the costs of these drugs. The introduction of generic versions of risperidone, quetiapine and olanzapine between 2006 and 2008 resulted in substantially lower prices for these products. In 2010, the Ontario government, which at the time serviced a population of 13.2 million (including nearly 2 million older adults), with a health care budget of $\$ 46$ billion, reduced generic drug prices from $50 \%$ to $25 \%$ of the brand-name equivalent. ${ }^{13-15}$ Although

Competing interests: See the end of the article.

This article has been peer reviewed.

Correspondence to: Tara Gomes, GomesT@smh.ca

CMAJ Open 2016. DOI:10.9778/cmajo.20150095 
these events would be expected to decrease costs associated with antipsychotic drug therapy in Ontario, 3 new medications - paliperidone, ziprasidone and aripiprazole — soon received regulatory approval and were added to the Ontario Drug Benefit formulary. ${ }^{16-18}$

The impact of the competing forces of high relative cost and potential for rapid uptake of newer, brand-name agents marketed with favourable unintended-effect profiles ${ }^{19-22}$ and the greater availability and lower prices of generic drugs is uncertain. Accordingly, we investigated the effect of the introduction of the newer brand-name atypical antipsychotics (starting with paliperidone in 2009) on rates of prescribing of atypical antipsychotics, prevalence of brand-name antipsychotic use and related drug benefit expenditures.

\section{Methods}

We conducted a population-based serial cross-sectional timeseries analysis of Ontario residents aged 65 years or more who were dispensed an antipsychotic between Jan. 1, 2007, and Mar. 31, 2013. These patients have universal access to physician services, hospital care and publicly funded drugs through the Ontario Health Insurance Plan (OHIP) and the Ontario Drug Benefit. This study was approved by the Research Ethics Board of the Sunnybrook Health Sciences Centre, Toronto, Ontario.

\section{Data sources}

We used large population-based administrative databases to conduct the study. The databases were linked with the use of unique, encoded identifiers and were analyzed at the Institute for Clinical Evaluative Sciences, Toronto. The Ontario Drug Benefit database contains records of all prescriptions dispensed to public drug plan recipients in Ontario. We used this database to identify the number and cost of all prescriptions for atypical antipsychotics dispensed over the study period. The OHIP Registered Persons Database contains basic demographic information (including date of birth, sex and date of death) for all residents of Ontario who have ever received a health card. Finally, the Contact Database combines OHIP registration data and data on use of health care services to maintain a list of people eligible for physician and hospital services in Ontario. We used it to determine the size of the population of OHIP-eligible people over the study period. The Contact Database was unavailable for the last quarter of the study period; therefore, we generated a quadratic least squares regression model to obtain population estimates for this final time point $\left(R^{2}=0.997\right)$.

\section{Rates of atypical antipsychotic use}

We examined the use of all atypical antipsychotics that were listed on the Ontario Drug Benefit formulary over the study period: quetiapine, olanzapine, risperidone, paliperidone, ziprasidone and aripiprazole. In each calendar quarter of the study period, we identified all people aged 65 years or more who filled at least 1 prescription for an atypical antipsychotic, and we report the number of patients who used atyp- ical antipsychotics, overall and stratified by atypical antipsychotic agent. We calculated rates of atypical antipsychotic use as a proportion of the population of OHIP-eligible Ontario residents aged 65 or more who were alive at the beginning of each quarter.

\section{Prevalence of use of brand-name agents and antipsychotic expenditures}

For each quarter, we determined the total quarterly cost to the provincial drug plan of atypical antipsychotic prescriptions dispensed to patients aged 65 or more and estimated the average cost per prescription. This analysis was conducted overall and stratified by atypical antipsychotic agent. To estimate the quarterly market share of brand-name prescriptions, we then classified all atypical antipsychotic prescriptions according to their generic status and found the proportion of prescriptions that were for brand-name agents.

\section{Statistical analysis}

We conducted a time-series analysis using interventional autoregressive integrated moving-average models to examine the impact of the introduction of new brand-name atypical antipsychotics on overall rates of use of these drugs. Given the close temporal relation of the new agents' introduction, we chose the marketing of the first new agent (paliperidone, in the third quarter of 2009) as our main intervention point in the model (see Appendix 1, available at www.cmajopen.ca/ content/4/2/E292/suppl/DC1). We used the correlograms depicting autocorrelation, partial autocorrelation and inverse autocorrelation functions to guide initial model selection. We assessed autocorrelation at various lags using the Ljung-Box $\chi^{2}$ statistic and stationarity using the augmented DickeyFuller test. Our intervention was modelled as a step function in the regression model. A $p$ value of less than 0.05 was considered statistically significant. All analyses were conducted with the use of SAS software version 9.2.

\section{Results}

\section{Overall atypical antipsychotic use and choice of agent}

We identified 235267 Ontario adults aged 65 years or more who were prescribed an atypical antipsychotic between Jan. 1, 2007, and Mar. 31, 2013. On average, atypical antipsychotic users were aged 79 years (SD 8.9), and 93200 (39.6\%) were men. Risperidone was the most commonly used agent at the beginning of the study period (13.0 users per 1000 older adults, $n=23107)$, followed by quetiapine (9.3 users per 1000 older adults, $n=16436$ ) and olanzapine (7.6 users per 1000 older adults, $n=13570$ ) (Figure 1). Over the subsequent 6 years, quetiapine use rose, and in the first quarter of 2013 it was the most commonly used atypical antipsychotic, with a prevalence of 15.1 users per 1000 older adults $(n=$ 32 532) (Figure 1). Following the introduction of new brandname agents in 2009, their use increased, reaching a high of 1.5 users per 1000 older adults $(n=3132)$ by the end of the study period. This rise was driven largely by the use of 


\section{OPEN}

Research

aripiprazole, which reached a rate of 1.0 user per 1000 older adults $(n=2120)$ (Figure 1$)$. Overall, the introduction of brand-name agents led to a small but statistically significant increase in the overall rate of atypical antipsychotic use, from 27.6 users per 1000 older adults in the third quarter of 2009 to 29.1 users per 1000 older adults by the end of the study period $(p=0.04)$ (Figure 2$)$.

\section{Market share of brand-name agents and atypical antipsychotic expenditures}

Following the introduction of generic versions of olanzapine and quetiapine, between the start of the study period and the second quarter of 2009, the prevalence of use of brand-name antipsychotic agents decreased considerably, from $57.5 \%$ to
$6.1 \%$ (Figure 3). However, after new agents were introduced, in the third quarter of 2009, the prevalence of use of brandname agents began to rise and reached $11.7 \%$ by the end of the study period.

The costs for atypical antipsychotics were also greatly influenced by the introduction of generic formulations early in the study period as well as the decrease in government reimbursement for generic drugs in the third quarter of 2010. Following these changes, the average cost per atypical antipsychotic prescription fell from $\$ 26.46$ at the beginning of the study period to a low of $\$ 14.00$ in the fourth quarter of 2010 (Figure 3). Thereafter, the average cost per prescription rose by $17.1 \%$ to $\$ 16.39$.

In the first quarter of 2013, the newly introduced medications (paliperidone, ziprasidone and aripiprazole) were used

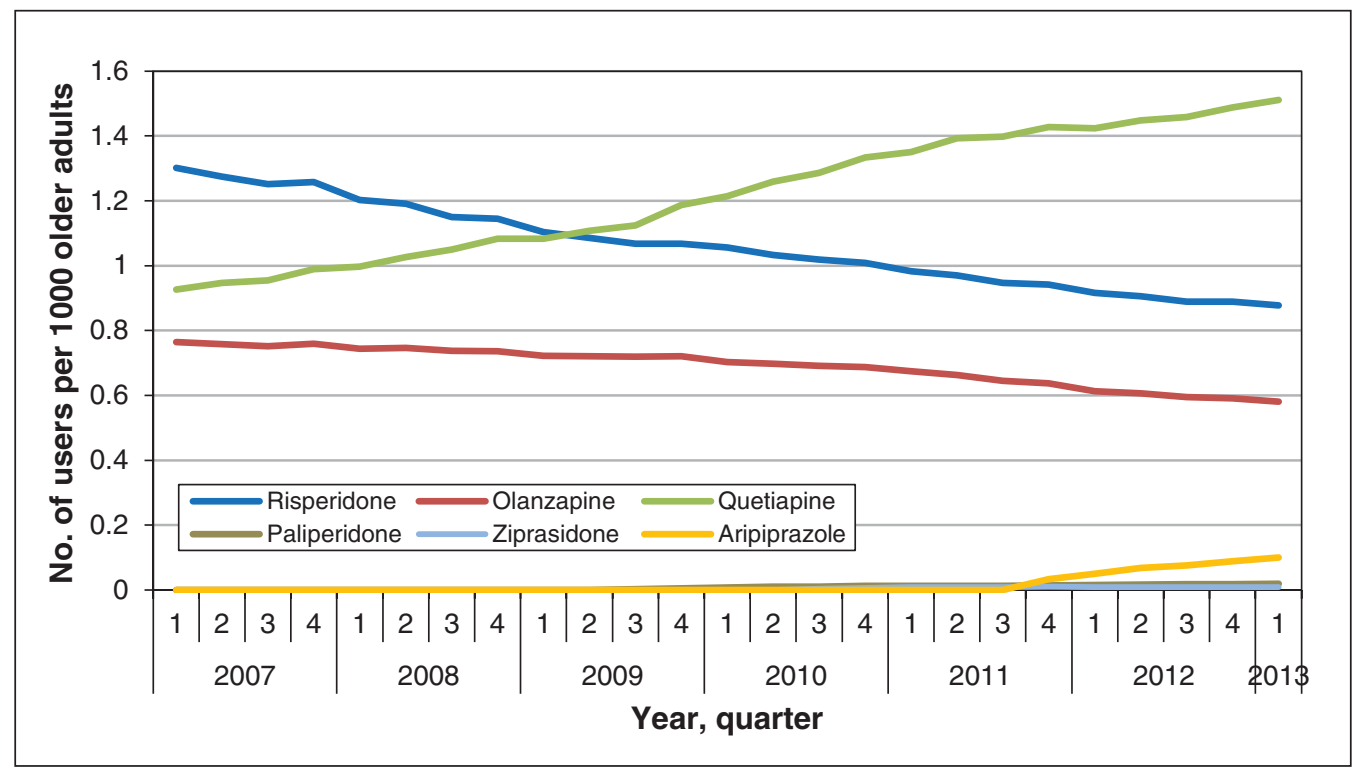

Figure 1: Prevalence of use of individual atypical antipsychotics among Ontario adults aged 65 years or more who were prescribed an atypical antipsychotic between Jan. 1, 2007, and Mar. 31, $2013(n=235267)$.

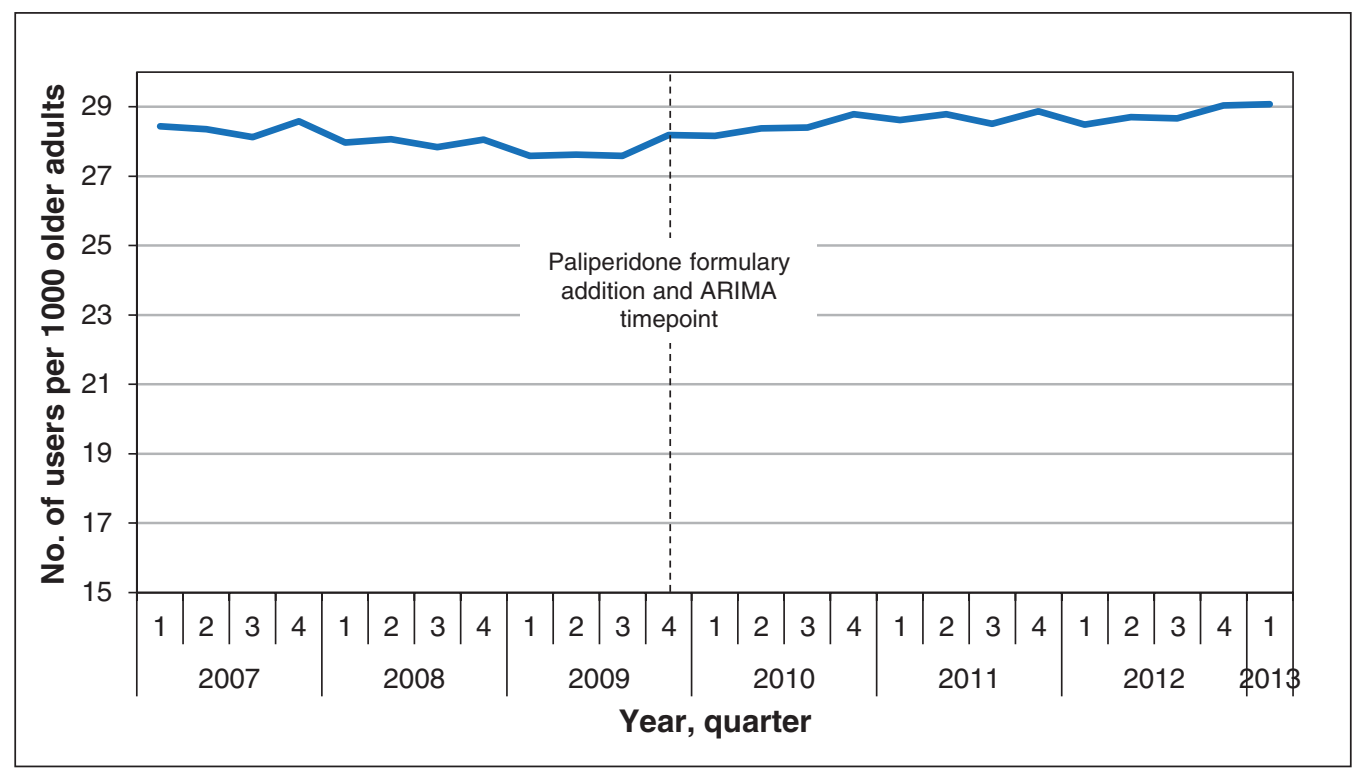

Figure 2: Rate of atypical antipsychotic prescribing per 1000 adults aged 65 years or more in Ontario. 
by $4.4 \%$ of atypical antipsychotic users but accounted for $14.1 \%$ of total atypical antipsychotic expenditures (\$1.2 million of $\$ 8.5$ million) (Table 1$)$. This discrepancy was driven by the large differential in the average quarterly costs per person for brand-name and generic agents. In the first quarter of 2013, average quarterly costs per user for paliperidone, ziprasidone and aripiprazole were \$953.76, \$362.64 and \$349.60, respectively. In comparison, the mean quarterly costs per patient for generic atypical agents at this time were $\$ 152.75$ for olanzapine, $\$ 110.41$ for risperidone and $\$ 104.59$ for quetiapine (Table 1).

\section{Interpretation}

We found large shifts in prescribing preferences and costs of atypical antipsychotics among older adults in Ontario over the study period as well as a modest but statistically significant overall increase in the rate of atypical antipsychotic prescribing following the introduction of new brand-name agents to the public drug formulary. As expected, we observed a marked decrease in expenditures corresponding with the introduction of generic agents and a reversal of this trend with the arrival of new agents. Although newer brand-name agents were used by less than $5 \%$ of atypical antipsychotic users in early 2013, these agents accounted for $14 \%$ of atypical antipsychotic costs. Furthermore, the growth of aripiprazole use showed no sign of slowing following its introduction, and given its high price compared with generic formulations, it is likely that costs for atypical antipsychotic agents will continue to rise in the near future.

Previous studies have shown expanding off-label prescribing and potential overuse of atypical antipsychotics..$^{1,2,7,8}$ This

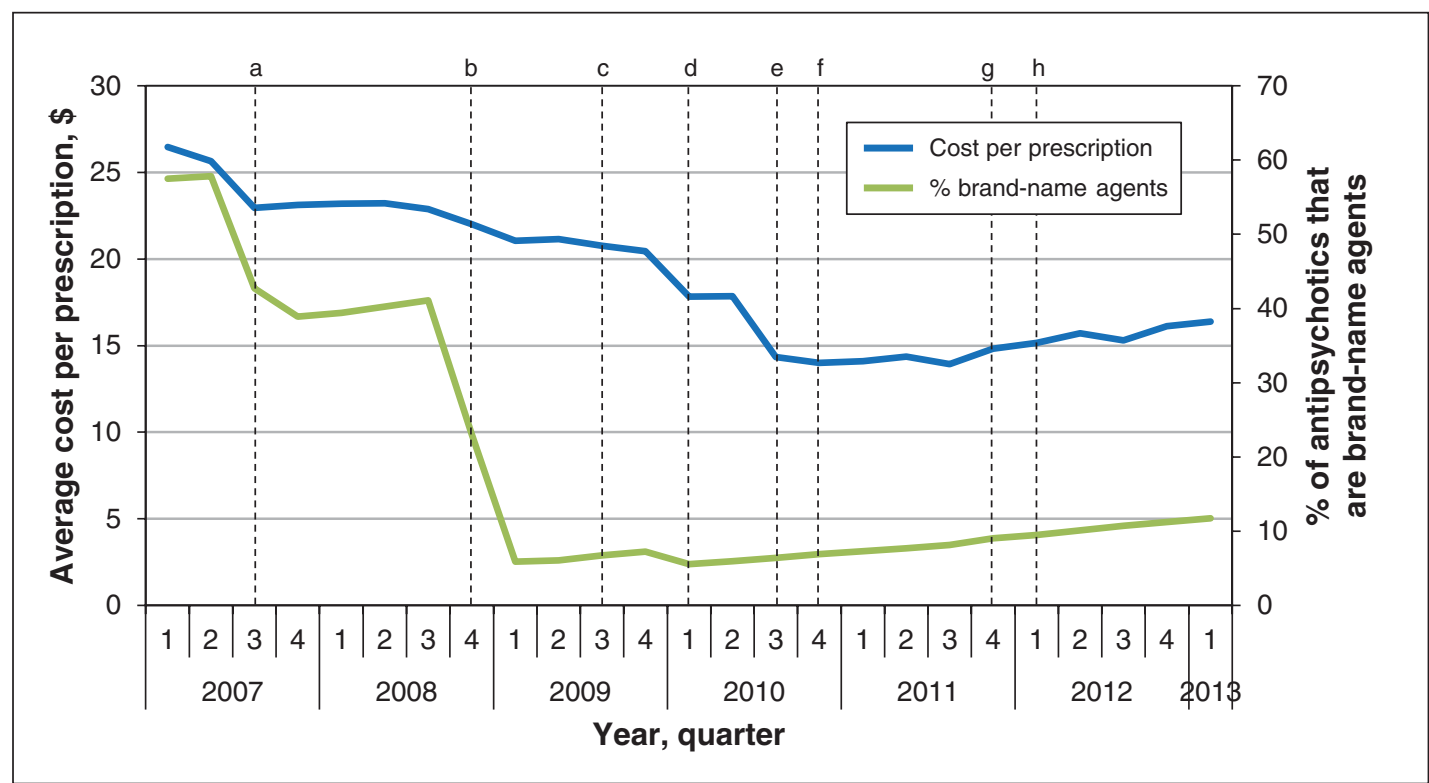

Figure 3: Average cost per atypical antipsychotic prescription and prevalence of use of brand-name atypical antipsychotic agents, 2007-2013. a: Olanzapine patent expiry. b: Quetiapine patent expiry. c: Paliperidone added to Ontario Drug Benefit formulary. d: Olanzapine rapid-dissolve patent expiry. e: Quetiapine extended-release added to formulary. f: Ziprasidone added to formulary. g: Aripiprazole added to formulary. h: Injectable paliperidone added to formulary.

Table 1: Total quarterly costs and cost per user of atypical antipsychotics at the start and end of the study period

\begin{tabular}{|c|c|c|c|c|c|c|}
\hline \multirow[b]{2}{*}{ Atypical antipsychotic } & \multicolumn{3}{|c|}{ First quarter 2007} & \multicolumn{3}{|c|}{ First quarter 2013} \\
\hline & Total cost, \$ & $\%$ overall costs & Cost per user, $\$$ & Total cost, \$ & $\%$ overall costs & Cost per user, $\$$ \\
\hline Overall & 10993284 & - & 217.74 & 8518981 & - & 137.58 \\
\hline Risperidone & 2201115 & 20.0 & 95.26 & 2061866 & 24.2 & 110.41 \\
\hline Olanzapine & 5815987 & 52.9 & 428.59 & 1890328 & 22.2 & 152.75 \\
\hline Quetiapine & 2976182 & 27.1 & 181.08 & 3365143 & 39.5 & 104.59 \\
\hline Paliperidone & - & - & - & 394855 & 4.6 & 953.76 \\
\hline Ziprasidone & - & - & - & 65639 & 0.8 & 362.64 \\
\hline Aripiprazole & - & - & - & 741151 & 8.7 & 349.60 \\
\hline
\end{tabular}




\section{OPEN}

suggests that the rising rate of use of these products after the introduction of new agents should be further monitored and explored to assess the appropriateness of prescribing practices. Furthermore, the safety of antipsychotic use in older patients has been questioned, particularly for the symptomatic treatment of behavioural and psychological symptoms of dementia. ${ }^{2,12}$ Adverse effects observed include extrapyramidal symptoms and increased risk of diabetes, hip fracture and allcause mortality. ${ }^{6,23-25}$ Notably, Health Canada and Janssen Inc. recently agreed to limit risperidone use in dementia to short-term symptomatic treatment of behavioural or psychological symptoms of severe Alzheimer-type dementia, citing a higher risk of cerebrovascular adverse events. ${ }^{26}$ However, past studies have shown safety warnings to be ineffective at reducing the use of antipsychotics among the older population in Canada and Europe. ${ }^{2,12}$ The manufacturers and Health Canada issued warnings regarding the safety of risperidone and olanzapine in 2002 and 2004, respectively, and a blanket statement urging caution in geriatric use of atypical antipsychotics followed in $2006 ;^{2}$ our data show a corresponding decrease in risperidone and olanzapine prescribing countered by an increase in quetiapine use, which resulted in no observable net effect on use of this drug class. Although prescribing preferences have shifted within the class as product availability has changed, atypical antipsychotics are increasingly a mainstay of geriatric psychiatry despite these safety concerns.

\section{Limitations}

Several limitations of this study warrant emphasis. First, we were unable to access in-hospital medication records, and thus our study is restricted to atypical antipsychotic use among older adults living in the community and in longterm care. Second, we assessed overall patterns of use and not patient information (e.g., diagnoses) or prescription information (e.g., dosage, length of use); therefore, we were unable to draw conclusions regarding the appropriateness of the observed prescribing habits or the clinical reasoning underlying the observed preferences for certain agents. Third, owing to the close temporal proximity of the introduction of new antipsychotic agents and generic versions of existing agents, we were unable to assess the independent impact of each new antipsychotic agent on drug expenditures using time-series analysis.

\section{Conclusion}

Our results suggest that the introduction of new atypical antipsychotic agents led to a small but statistically significant increase in the overall use of these medications in Ontario. Possible reasons for this increase include increased marketing of brand-name agents and a relative paucity of third-party data concerning medium- to long-term risk of adverse effects. ${ }^{27-30}$ Furthermore, we showed that, despite a drop in atypical antipsychotic costs following the introduction of several generic formulations, expenditures related to these agents began to rise in 2011, after the introduction of several new, brand-name agents. Further monitoring of these trends and their impact on patient outcomes and health sector expenditures would be prudent as they have the potential to have considerable effects on quality of care and drug formulary budgets.

\section{References}

1. Rapoport M, Mamdani M, Shulman KI, et al. Antipsychotic use in the elderly: shifting trends and increasing costs. Int 7 Geriatr Psychiatry 2005;20: 749-53.

2. Valiyeva E, Herrmann N, Rochon PA, et al. Effect of regulatory warnings on antipsychotic prescription rates among elderly patients with dementia: a population-based time-series analysis. CMA7 2008;179:438-46.

3. Alexander GC, Gallagher SA, Mascola A, et al. Increasing off-label use of antipsychotic medications in the United States, 1995-2008. Pharmacoepidemiol Drug Saf 2011;20:177-84.

4. Leslie DL, Mohamed S, Rosenheck RA. Off-label use of antipsychotic medications in the department of Veterans Affairs health care system. Psychiatr Serv 2009;60:1175-81.

5. Chen H, Reeves JH, Fincham JE, et al. Off-label use of antidepressant, anticonvulsant, and antipsychotic medications among Georgia Medicaid enrollees in 2001. 7 Clin Psychiatry 2006;67:972-82.

6. Maher AR, Maglione M, Bagley S, et al. Efficacy and comparative effectiveness of atypical antipsychotic medications for off-label uses in adults: a systematic review and meta-analysis. 7AMA 2011;306:1359-69.

7. Rochon PA. Exploring the variation in Ontario nursing home prescribing rates for antipsychotics. Healthc Q 2007;10:20-2.

8. Rochon PA, Stukel TA, Bronskill SE, et al. Variation in nursing home antipsychotic prescribing rates. Arch Intern Med 2007;167:676-83.

9. Spielmans GI, Berman MI, Linardatos E, et al. Adjunctive atypical antipsychotic treatment for major depressive disorder: a meta-analysis of depression, quality of life, and safety outcomes. PLoS Med 2013;10:e1001403.

10. Dewa CS, Remington G, Herrmann N, et al. How much are atypical antipsychotic agents being used, and do they reach the populations who need them? A Canadian experience. Clin Ther 2002;24:1466-76.

11. Chen Y, Briesacher BA, Field TS, et al. Unexplained variation across US nursing homes in antipsychotic prescribing rates. Arch Intern Med 2010;170: 89-95.

12. Schulze J, van den Bussche H, Glaeske G, et al. Impact of safety warnings on antipsychotic prescriptions in dementia: nothing has changed but the years and the substances. Eur Neuropsychopharmacol 2013;23:1034-42.

13. Law MR, Ystma A, Morgan SG. The short-term impact of Ontario's generic pricing reforms. PLoS One 2011;6:e23030.

14. Population by year, by province and territory (Number). Ottawa: Statistics Canada. Available: www.statcan.gc.ca/tables-tableaux/sum-som/101/cst01/ demo02a-eng.htm (accessed 2015 Nov. 10).

15. 2010 Ontario budget: Chapter II: Ontario's economic outlook and fiscal plan. Section H: details of Ontario's finances. Toronto: Ontario Ministry of Finance; 2010. Available: www.fin.gov.on.ca/en/budget/ontariobudgets/2010/ch2h. html\#t31_fnl (accessed 2016 May 26).

16. Update $\bar{K}$ : Ontario drug benefit formulary/comparative drug index No. 41 (effective August 18, 2009). Toronto: Ontario Ministry of Health and LongTerm Care; 2009.

17. Update U: Ontario drug benefit formulary/comparative drug index No. 41 (effective October 28, 2010). Toronto: Ontario Ministry of Health and LongTerm Care; 2010.

18. Update AB: Ontario drug benefit formulary/comparative drug index No. 41 (effective October 25, 2011). Toronto: Ontario Ministry of Health and LongTerm Care; 2011. Available: www.health.gov.on.ca/en/pro/programs/drugs/ formulary/41_update_ab_20111014.pdf (accessed 2015 Jan. 13).

19. Drake R, Skinner J, Goldman HH. What explains the diffusion of treatments for mental illness? Am 7 Psychiatry 2008;165:1385-92.

20. Liu Q. The dynamics of competitive drug detailing. Ithaca (NY): The Johnson School at Cornell University; 2007. Available: www.chicagobooth. edu/research/workshops/marketing/docs/Liu-jobpaper.pdf (accessed 2016 May 26).

21. Hoffman MN. Pharmaceutical detailing is not for everyone: side effects may include sub-optimal prescribing decisions, compromised patient health, and increased prescription drug spending. 7 Leg Med 2012;33:381-97.

22. Spurling GK, Mansfield PR, Montgomery BD, et al. Information from pharmaceutical companies and the quality, quantity, and cost of physicians' prescribing: a systematic review. PLoS Med 2010;7:e1000352.

23. Schneider LS, Dagerman KS, Insel P. Risk of death with atypical antipsychotic drug treatment for dementia: meta-analysis of randomized placebocontrolled trials. FAMA 2005;294:1934-43.

24. Gill SS. Antipsychotic drug use and mortality in older adults with dementia. Ann Intern Med 2007;146:775-86.

25. Jalbert JJ, Eaton CB, Miller SC, et al. Antipsychotic use and the risk of hip fracture among older adults afflicted with dementia. $7 \mathrm{Am} \mathrm{Med} \mathrm{Dir} \mathrm{Assoc}$ 2010;11:120-7. 
26. Risperidone - restriction of the dementia indication. Toronto: Janssen; 2015. Available: healthycanadians.gc.ca/recall-alert-rappel-avis/hc-sc/2015/43797a -eng.php (accessed 2016 May 26).

27. Oldani MJ. Thick prescriptions: toward an interpretation of pharmaceutical sales practices. Med Anthropol Q 2004;18:325-56.

28. Liu Q, Gupta S, Venkataraman S, et al. An empirical model of drug detailing: dynamic competition and policy implications. Manage Sci 2015 Dec. 10 [Epub ahead of print].

29. Adair RF, Holmgren LR. Do drug samples influence resident prescribing behavior? A randomized trial. Am 7 Med 2005;118:881-4.

30. Lee K, Bacchetti P, Sim I. Publication of clinical trials supporting successful new drug applications: a literature analysis. PLoS Med 2008;5:e191.

Competing interests: Muhammad Mamdani has served as an advisory board member for AstraZeneca, Bristol-Myers Squibb Canada, Eli Lilly and Company, GlaxoSmithKline, Hoffmann-La Roche Limited, Novartis Phamarceuticals Canada Inc., Novo Nordisk and Pfizer Canada Inc. No other competing interests were declared.

Affiliations: Schulich School of Medicine and Dentistry (Foster), Western University, London; Institute for Clinical Evaluative Sciences (Camacho, Vigod, Yao, Juurlink, Paterson, Mamdani, Martins, Gomes), Toronto; Applied Health Research Centre (Foster, Mamdani, Gomes), St. Michael's Hospital, Toronto; Women's College Hospital and Research Institute (Vigod), Toronto; Departments of Medicine (Juurlink) and Psychiatry (Vigod) and Institute of Health Policy, Management and Evaluation (Vigod, Juurlink, Paterson, Mamdani, Gomes), University of
Toronto, Toronto; Department of Family Medicine (Paterson), McMaster University, Hamilton, Ont.

Contributors: Paul Foster, David Juurlink, Michael Paterson, Muhammad Mamdani and Tara Gomes conceived the study. Ximena Camacho, Zhan Yao and Diana Martins acquired the data. Paul Foster and Tara Gomes drafted the manuscript, and Simone Vigod, David Juurlink, Michael Paterson, Muhammad Mamdani and Tara Gomes revised the manuscript for important intellectual content. All of the authors designed the study, contributed to data analysis and interpretation, gave approval of the final version to be published and agreed to act as guarantors of the work.

Funding: This study was supported by the Ontario Drug Policy Research Network, which is funded by grants from the Ontario Ministry of Health and Long-Term Care (MOHLTC) Health System Research Fund. It was also supported by the Institute for Clinical Evaluative Sciences (ICES), which is funded by an annual grant from the Ontario MOHLTC.

ICES disclaimer: This study was supported by the ICES, which is funded by an annual grant from the Ontario MOHLTC. The opinions, results and conclusions reported in this article are those of the authors and are independent from the funding sources. No endorsement by the ICES or the Ontario MOHLTC is intended or should be inferred.

Supplemental information: For reviewer comments and the original submission of this manuscript, please see www.cmajopen.ca/content/4/2/ E292/suppl/DC1 